Article

\title{
Cruise Tourism for Sustainability: An Exploration of Value Chain in Shenzhen Shekou Port
}

\author{
Yanhong Liu ${ }^{1,2} \mathbb{1}$, Erwei Dong ${ }^{3,4}$, Shiqi Li $^{2}$ and Xiaowen Jie ${ }^{1, *}$ \\ 1 Business School, Sichuan University, Chengdu 610065, China; lucyliu@szu.edu.cn \\ 2 Normal College, Shenzhen University, Shenzhen 518060, China; lishiqi718@163.com \\ 3 School of Community Resources and Development, Arizona State University, Phoenix, AZ 85004, USA; \\ edong1@asu.edu \\ 4 International Joint Tourism College, Hainan University-Arizona State University, Hainan University, \\ Haikou 570228, China \\ * Correspondence: jiexw@vip.163.com
}

Received: 24 February 2020; Accepted: 8 April 2020; Published: 10 April 2020

\begin{abstract}
Based on the support of governmental policies and the rapid growth of China's economic development, residents' living standards, and tourism consumption demand, cruise tourism has continuously developed and its service level has gradually improved, which have become the main driving forces for the sustainable growth of China's cruise tourism industry. This paper took Shenzhen Shekou Port (SSP) as a research site and used an online text analysis method by Rost Content Mining 6 software to analyze 2552 Ctrip travel network, and then did further study through face to face interviews from the perspective of "tourists source" and "procurement" in the value chain theory. Only by understanding the developing trend of cruise tourists can we cultivate cruise culture, expand cruise tourism market, and finally realize the benign development of cruise tourism. The research results show that the cruise business in Shenzhen should strengthen the senior citizens market and marketing to kids and parents, and improve the satisfaction of cruise passengers in terms of enriching entertainment facilities, elevating service quality, and upgrading duty-free shopping centers. This paper not only focused on the study of cruise tourists in Southern China, but also enriches the research of the cruise value chain.
\end{abstract}

Keywords: cruise tourism; sustainable development; value chain; Shenzhen Shekou Port

\section{Introduction}

The cruise industry has become a significant component of the tourism economy over the past several years [1]. The development of cruise tourism brings strong power and new trends and implications for research on consumer engagement [2]. Cruise tourism, as a new industry produced by the combination of transportation and tourism, has considerable development space, applying the relatively new concept of customer experience management to the pre-consumptive stage within a cruise tourist's journey [3]. Nowadays, cruise tourism has been developed preliminarily in Asia, and supported gradually by different countries and their governments. What can we dig from online cruiser reviews, to understand their experience and satisfaction so as to take further action? [4]. Moreover, international cruise companies also attach great importance to it, especially port operators who are main participants [5], including cruise port centrality and target marketing [6]. What do cruise tourists care about while traveling? Value chain theory offers new vision for our cruise tourism study.

We used the value chain theory of Porter (1985), which enabled us to find the favorable information of enterprise profit growth in the link where customers create reproducible value [7]. We were concerned with customer perception, which is one of the important factors in customer satisfaction, 
which ultimately determines customers' repurchase intention or brand loyalty and provides competitive advantages for enterprises [8]. It cannot be ignored that the support of local residents and enterprises to tourism development will promote the healthy development of tourism and the successful development of the community [9]. With the efforts of leading roles, including tourists and local enterprises, a new development path of green value chain in the tourism industry was explored to provide some guidance and reference for tourism theory and practice [10].

The past decades have seen the rapid development of cruise research. More and more scholars study mainland Chinese cruise passengers' experiences [11]. With the support of government policies and in combination with the rapid growth of China's economy, residents' living standards, and tourism consumption demand, marine tourism products represented by cruise tourism have been continuously improved and the service level has been gradually improved, becoming one of the main driving forces for the sustained growth of China's tourism [12]. Cruise has become the "fourth way of travel", which is parallel with cars, trains, and planes. Cruise tourism products have gradually become an attractive leisure lifestyle [13]. Nevertheless, how to grab the cruise travel segment from China's huge market needs our further exploration.

From the perspective of cruise industry value chain, China's tourism industry has basically completed the stage of infrastructure construction characterized by port construction and started to leapfrog into the stage of cruise tourism featuring port reception, ticket agents, and tourist services [14]. Although Shenzhen Shekou Port only ranks the fourth among the eight international cruise home ports in China, Shenzhen has its unique characteristics, such as being located in the forefront of China's reform and opening up as the region with the fastest economic development and the most active customer market [15]. The choice of Shenzhen for terminal study can explore the focus factors that Chinese cruise tourists are concerned about in their leisure tourism activities so as to add the value of expanding the consumer market in the cruise industry chain. In addition, this paper also presents the results of a study of developing the potential cruise customer market in China.

\section{Sustainable Cruise Tourism in Shenzhen, China}

Cruise tourism is a high-end service industry, involving all aspects of economy and society, among which policy environment is the core factor in cruise development [16]. Cruise tourism emerged in the early 19th century, and its initial business was to undertake sea freight activities. With the continuous development of tourism and the constant enrichment of tourism activity elements, cruise tourism has gradually developed into a complex emerging tourism format integrating life, recreation, and entertainment into one [17].

Cruise tourism has completed two stages in China since the late 1990s [18]. The first stage was basically dominated by the arrival of cruise from the late 1990s to 2010, mainly focusing on international cruise reception in Hong Kong, Tianjin, and Shanghai. The second stage was the rise of the home port route and the arrival route. With international cruise-related companies' efforts, China became the emerging market in the world [19]. From 2005 to 2015, the number of cruise tourists increased by $266.1 \%$ in every region except North America and Europe. The Asia-Pacific region, especially China, has the highest contribution rate. According to the International Cruise Association and Cruise Industry News 2017-2018 annual report examining the global cruise tourism market by country, the United States is still dominant, with cruise visitors numbering up to 11.52 million people, nearly $50 \%$ of the total number of global cruise visitors [20]. China, for the first time, ranked second with 2.1 million entry-exit cruise tourists, accounting for about $10 \%$ of the international cruise market share [21]. Collectively, these studies outline a critical role for Chinese cruise tourism leisure market.

Shenzhen Shekou Port (SSP), also known as Shenzhen CMSK International Cruise Home Port, was selected as the research site. It is located in the estuary of the Pearl River in the southwest of Shenzhen, Guangdong and faces Yuen Long in the New Territories of Hong Kong across the sea, connecting Hong Kong with the mainland. This port area is an important port led by the Merchant Shekou Group, with a construction area of 1.7 million square meters and an area of 690,000 square meters, which greatly 
promotes the openness of Shenzhen's economy, cultural diversity, and international exchanges. SSP mainly has four functional groups, which are business, residential life, cruise center, and cultural and creative arts. Up to now, this modern international cruise home port in Southern China is the only one integrating "sea, land, air, and iron", which can meet the needs of the world's largest cruise ships and give full play to the role of "maritime gateway" to promote the connection between Hong Kong and Shenzhen. SSP became the pilot port of "China Cruise Tourism Development Experimental Zone" in May 2016, exploring the industrial model of "front port, central district, and back city" with cruise home port as the core, injecting more vitality into the cruise tourism market in Southern China [15].

Cruise tourism is a part of the sustainable development of national leisure life. In-depth research on cruise tourism has a direct impact on its development potential and economic efficiency [22]. The cruise tourism industry has experienced significant growth in recent years and has a very positive outlook for the future [23]. Cruise tourism should be given a segment of travel worldwide [24]. While rapid increases in cruise tourists and port construction have been observed in China, leisure research on cruise tourism in China remains unavailable. However, the case study of SSP highlights the need for it.

\section{Cruise Company Value Chain}

The value chain theory was developed by Michael E. Porter in 1985 as a tool for analyzing the competitive advantage of enterprises. Value-added activities of value chain can be divided into basic value-added activities and auxiliary value-added activities. The basic value-added activities of an enterprise are the "production and operation links" in the general sense, such as material supply, finished product development, production and operation, finished product storage and transportation, marketing, and after-sales service. These activities are directly related to the processing flow of commodity entities. Subsidiary value-added activities of the enterprise include organizational construction, personnel management, technology development, and procurement management. As for cruise-related companies, the value chain refers to the economic activities of each production and business activity. All of the production and operation activities that are not identical but are interrelated in cruise companies constitute a dynamic process of creating value [25].

Figure 1 indicates the value chain for a cruise-related company. Company infrastructure includes daily operations management, investment promotion, financial accounting, and other activities. Human resource management includes recruitment, training, labor dispatch, and other related activities. Technological development includes the design and development of cruise lines, innovative tourism products, and other activities. Procurement includes liaison, negotiation, ordering, maintenance, and other activities with suppliers of cruise-related products. Tourists sources include customer contact, communication, research, marketing, planning, operation, after-sales service, and other activities.

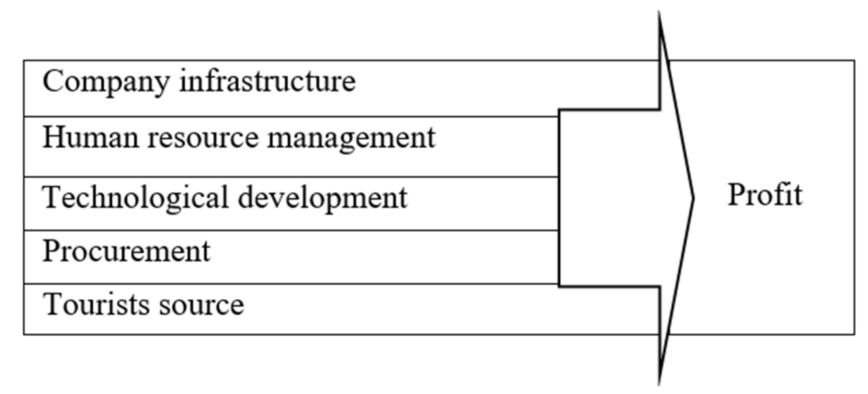

Figure 1. Sketch map of cruise company value chain. Source: Adopted from Liu et al. Sketch map of value chain [25].

Liu et al. (2017) argued that effective and flexible use of value chain makes related companies realize value increment and further realize value chain proliferation [25]. As shown in Table 1, from the development perspective of the number, speed, and profit model listed in the longitudinal column, 
the value chain increment refers to the single strand shown in the value chain with low speed for cost plus profit model of value chain added value. Value chain proliferation refers to two or more chains shown in the value chain with fast speed for profit model of copying with the value chain to expand reproduction effect on the road to success. From the value chain increment to value chain proliferation, it is an orderly and progressive process [25].

Table 1. Statement of value chain increment and proliferation.

\begin{tabular}{ccc}
\hline \multirow{2}{*}{ Development } & \multicolumn{2}{c}{ Comparative Statement } \\
\cline { 2 - 3 } & Value Chain Increment & Value Chain Proliferation \\
\hline number & single-strand & two or more chains \\
\hline speed & low & fast \\
\hline model & cost plus profit & $\begin{array}{c}\text { copying with the value chain to } \\
\text { expand reproduction effect }\end{array}$ \\
\hline
\end{tabular}

Source: Liu et al. Value chain increment and proliferation [25].

Penco and Profumo (2019) addressed the antecedents of cruise companies' strategy implementation, focusing on mergers, acquisitions, and alliances as potential alternative choices for managers [26]. Sun and Feng (2012) regarded cruises as a complex social economy system concerning people, organization, and interactive effect between geographical entities formed by a way of maritime transport [27]. Zhang et al. (2010) emphasized that the cruise tourism industry can develop various elements, such as those based on the perspective of industry chain, and believed that cruise tourism refers to the series of activities of integrated services, sightseeing leisure industry, transportation, travel, and tourism industry of the marginalized enterprise [28]. Luo et al. (2011) believed that the cruise ship hull itself can realize various tourism functions, such as shopping, leisure, fitness, catering, etc., which is a new kind of tourism with strong plasticity. International cruise companies are also scrambling to open more cruise lines [19]. Many cruise destinations around the world not only regard cruise tourism as a direct source of economic income, but also an important means to attract more land-based tourists to the region [29]. Li (2015) mainly cared about two levels of research on cruise ships: from a macro perspective, it mainly explained the economic characteristics, spatial structure, radiation effect of the cruise tourism industry, and the countermeasures and strategies for market development. At the micro level, it is mainly used to evaluate the competitiveness of cruise ports and analyze port customs clearance policies, talent cultivation, and company operation strategies, etc. [30]. Guan and Wu (2014) found that cruise passengers have high satisfaction with the service quality of crew and route design, but low satisfaction with the cruise's own hardware facilities, such as Internet cafes and libraries [31]. Hu et al. (2018) believed that cruise tourism satisfaction is affected by external perception and internal motivation, among which external perception includes cruise facilities, prices, and entertainment activities, and internal motivation includes displaying status and communication, etc. [32]. Liu et al. (2019) tested cruise line customers' responses to risk and crisis communication messages addressing health-related incidents on cruise ships. In view of all that has been mentioned so far, one may suppose that cruise companies need good and solid infrastructure [33].

Chen et al.'s (2019) research found that factors such as the number of passengers, number of crew members, number of cruise lines, expenditure per passenger, and expenditure per cruise line are positively correlated to cruise economy. Moreover, the cruise line has an obvious regulating effect on the expenditure of each passenger and each crew in the port destination [34].

The study presented thus far provides evidence that human resource management has an important and significant function.

Han et al. (2019) explicated cruise travelers' decision formation for choosing an environmentally responsible cruise product rather than a conventional cruise because the cruise industry has faced the greening issue [35]. Petrick (2005) classified the contents affecting the quality of cruise tourism into 
tangible and intangible parts, in which the tangible part includes internal public areas, passenger cabins, and external decks, while the intangible part includes flavor, food, entertainment, shore excursions, port calls, etc. [36]. According to the research, the influence of the tangible parts is reflected in the basic product quality perception, while the intangible factors are more critical. Considering all of this evidence, it seems that technological development has a long way to go.

As for facilities and service procurement attributes, Shen (2018) believed that external factors are changing, such as public safety and health emergencies and increasingly fierce international competition, which pose new challenges to the tourism industry, and tourists themselves pay more attention to the improvement of safety and comfort of tourism experience. In addition, with the complex needs of tourists, the tourism industry will provide more customer-oriented products and services [37].

Nolich et al. (2019) regarded the cabin as a home and introduced a novel comfort optimization framework for IoT-equipped smart environments and applications on cruise ships [38]. Nur et al. (2019) discussed the revenue management in the cruise line industry [39]. Miles (2019) gave the suggestion that the cruise experience represents a mode of consumption in which the consumer effectively becomes the product [40].

A great deal of previous research into cruise tourists resources has focused on tourists' satisfaction, which will greatly promote the continuous expansion of cruise market, the improvement and optimization of service quality, and the promotion in the international cruise field [41]. Papathanassis (2012) found that passenger interaction plays a significant role in promoting customer satisfaction, providing a potential opportunity for cruise lines to distinguish themselves from their competitors [42]. Han and Hyun (2019) verified the imperative role of motivations, values, image, desire, and relationship investment in generating repeat cruising intentions [43]. Hosany and Witham (2010) analyzed the tourist cruise experience dimension and recommendation intention and satisfaction in the entertainment, aesthetic, and education, from four dimensions of experience, had the strongest influence on satisfaction and recommendation intention, while aesthetic experience, entertainment, education, and escape had different degrees of influence [44]. Silvia et al. (2019) not only regarded familiarity and visit characteristics as determinants of tourists' experience at a cruise destination, but also cared about the impact of crowding on visitors' satisfaction for the sustainability of cruise tourism onshore $[45,46]$.

Fernandez et al. (2019) further studied cruise passengers' intention and sustainable management of cruise destinations [47]. Daniela et al. (2019) confirmed that culture affects sentiments expressed in cruise tours' electronic word-of-mouth (eWOM) [48]. Chua et al. (2019) investigated cruise vacationers' behavioral intention formation in the fast-growing cruise industry from the moderating impact of gender and age [49]. Aleksandar (2019) studied the buyer role played by children in the selection of cruise lines and found that children played a very important role in the purchase decision process. Children's autonomy on board should be valued so that they and their families can create memorable and distinctive cruise experiences [50].

Brejla and Gilbert (2012) jointly explored how the interaction between passengers and employees would affect the cruise service, and the conclusion showed that passenger experience is affected by public space and onboard service [51].

Tang et al. (2019) found that among Chinese adults with higher incomes, there are barriers to cruise travel from domestic ports, mainly due to lack of knowledge, time, and money [52]. Li (2019) explored the onshore travel experience of Chinese mainland tourists who have taken three international cruise ships from Shanghai to Japan and South Korea, and believed that cultural contact has a great impact on tourists [11]. Research on cruise tourism started relatively late in China, and Chinese scholars' research on cruise ships is comprehensive but broad, however, the research on the cruise leisure target market concerned with the south of China and key cruise ports is relatively deficient.

Therefore, the purpose of this research was to study what Chinese cruise tourists are caring about while travelling, who are the most important potential market, and what emotion they have so as to make them happy during the trip. Value chain of this paper was only involved in two parts, 
"tourists source" and "procurement", linking with how to understand the needs of the booming Chinese market, which concerns cruise production and business activities in cruise company value chain.

\section{Methods}

Network textual analysis is generated spontaneously by tourists with strong authenticity and great research value [53]. Gursoy studied consumers' information search behavior and the factors that are likely to influence their information search behavior and their utilization and processing of online reviews, especially their utilization of online reviews in their decision-making process [54]. Anyway, online consumer reviews have been studied for various research problems in hospitality and tourism [55]. The rapid development of the Internet has brought the prosperity of social media, and people are getting more and more accustomed to sharing their experience online. The traditional questionnaire method would have been difficult to adopt at SSP for the tourists in the departure hall as they have no cruise experience yet, while the travelers in the arrival hall are always eager to get back home in a hurry. Therefore, on one hand, this research used Rost Content Mining 6 software (hereinafter referred to as Rost CM6 software) to summarize and analyze effective comment data collected on Ctrip, which is the website with the highest overall ranking and one of the largest professional tourism websites in China, providing comprehensive services, a wide range of customers, and more comprehensive data. On the other hand, the interview method was used to collect the personal stories, experiences, and comments of the respondents in the cruise, being organized into effective data.

Firstly, referring to the research framework studied by Sun and Ni (2018) [56], we collected 2552 comments from January 2018 to March 2019 about Shenzhen cruises by selecting comments about the top four cruises: Costa Atlantica, MSC Splendida, Voyager of the Seas, and World Dream, using network text analysis method and conducting high-frequency word analysis, semantic network analysis, and emotion analysis. Under the influence of network language and tourists' writing habits, some words have the same meaning although they have different ways of being expressed, so they needed to be preprocessed on the basis of eliminating those that have nothing to do with the theme and repetitive comments. For such words, supplementary tools can be used. ROST CM6 software text substitution was used to transform words like "oil tanker" and "cruise ship" into an unified term, that is, "cruise". The use of "catering" means "meals" or "food", and so on. We excluded the high-frequency words such as "everyone" that were irrelevant to the study and had no impact on the research results. The unified transformation method is more conducive to accurate analysis and measurement.

Secondly, considering those aged tourists and parents with children who could not or would not make comments on networks, a further face-to-face interview method was adopted by taking a cruise of "World Dream" from SSP to Vietnam on December 9th to 13th, 2018. During the trip, 54 tourists were randomly interviewed to summarize and analyze their satisfaction with the trip. Considering 54 samples were far from adequate, 537 more online comments concerned with the "World Dream" were collected as supplementary to assure tourists' scores from cruise interviews and online texts were objective.

Finally, home port value chain analysis was made with an integrated study of emotion analysis and satisfaction analysis to focus on sustainability of the "tourists source" and "procurement" parts.

Above all, the whole research procedure is shown step by step in Figure 2. 


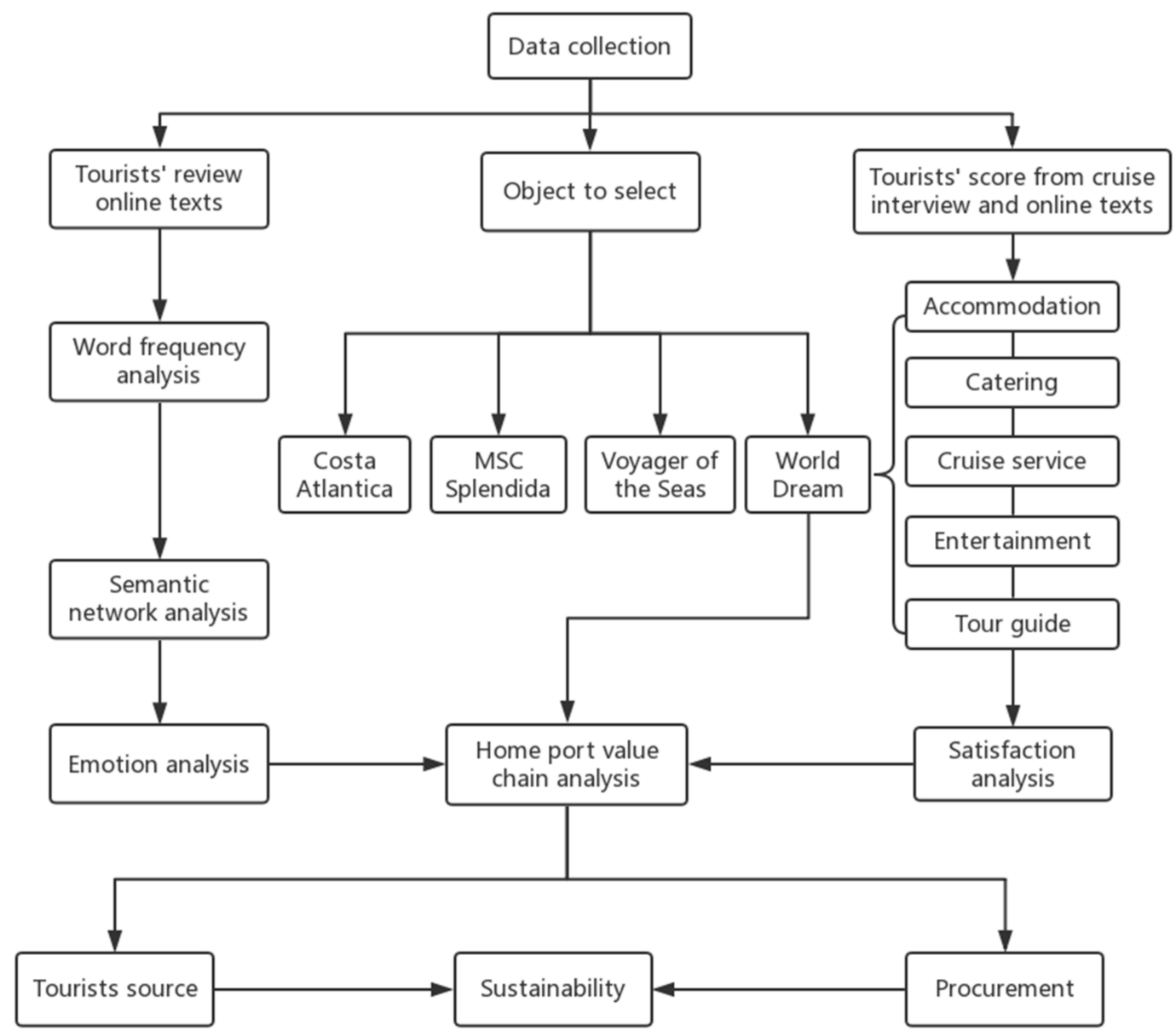

Figure 2. Procedure of the research.

\section{Results}

\subsection{Subsection High Frequency Word Statistics}

After sorting and analyzing the text documents, we generated the top 60 high-frequency words, as shown in Table 2.

From the top 10 of the highest frequency, "cruise", as the main body of cruise tourism, was the most frequently mentioned by tourists. As cruise tourism is an emerging noble form of fashioned tourism, the second-ranked "service" was also of particular concern to tourists. The third-ranked "itinerary" and the fifth-ranked "scenic spot" also reflect the characteristics of Chinese tourists, who mainly pay attention to the scenic spots on the shore and sightseeing. The fourth place "tour guide" reflects the importance of explaining and arranging the itinerary during the journey. As the cruise tour is mainly for group travel, local escorts and tour leaders play important roles. The sixth-ranked item was "shore", which reflects the attention of tourists to shore trips, and the fact that sightseeing is an important item in tourism. The seventh-ranked word "shopping" reflects the importance of "purchase" among the six elements of tourism. The eighth-ranked "facility" mainly refers to the entertainment facilities on the cruise, which are generally rated as "luxury" and "rich", but there are also a few comments on the closed entertainment facilities. The ninth-ranked word "catering" reflects the fact that Chinese people "take food as their top priority". Restaurants on cruise ships generally provide different kinds of catering needs according to tourists' preferences. The tenth-ranked "elderly" indicated that cruise tourism is a leisure and experiential health tourism, with a large proportion of tourists as elderly. Finally, "satisfy", "happy", "enjoy", and other positive words in the high-frequency vocabulary list appeared frequently in the evaluation. 
Table 2. Frequent word statistics of tourists' attention to cruise-related factors.

\begin{tabular}{|c|c|c|c|c|c|}
\hline No. & Characteristic Word & Frequency & No. & Characteristic Word & Frequency \\
\hline 1 & cruise & 3532 & 31 & program & 1461 \\
\hline 2 & service & 3324 & 32 & casino & 1439 \\
\hline 3 & itinerary & 3088 & 33 & enjoy & 1398 \\
\hline 4 & guide & 3081 & 34 & parents & 1377 \\
\hline 5 & scenic spot & 2779 & 35 & happy & 1361 \\
\hline 6 & shore & 2361 & 36 & tour & 1359 \\
\hline 7 & shopping & 2343 & 37 & friend & 1355 \\
\hline 8 & facility & 2309 & 38 & environment & 1350 \\
\hline 9 & catering & 2303 & 39 & luxury & 1234 \\
\hline 10 & elderly & 2211 & 40 & sightseeing & 1209 \\
\hline 11 & abundant & 2094 & 41 & sanitation & 968 \\
\hline 12 & experience & 2090 & 42 & management & 925 \\
\hline 13 & net work & 1989 & 43 & foreigner & 910 \\
\hline 14 & satisfy & 1877 & 44 & waste & 873 \\
\hline 15 & talk to passengers & 1864 & 45 & language & 869 \\
\hline 16 & staff attitude & 1851 & 46 & signpost & 841 \\
\hline 17 & room & 1846 & 47 & entertainment & 824 \\
\hline 18 & boarding & 1840 & 48 & weather & 762 \\
\hline 19 & show & 1835 & 49 & water activity & 743 \\
\hline 20 & child & 1829 & 50 & ocean & 706 \\
\hline 21 & disembark & 1811 & 51 & enthusiasm & 683 \\
\hline 22 & buffet & 1667 & 52 & appointment & 671 \\
\hline 23 & the first time & 1653 & 53 & toilet & 657 \\
\hline 24 & queuing & 1649 & 54 & considerate & 649 \\
\hline 25 & leisure & 1641 & 55 & quality & 643 \\
\hline 26 & next time & 1560 & 56 & visit & 624 \\
\hline 27 & children's area & 1522 & 57 & Japan & 611 \\
\hline 28 & easy to reach & 1519 & 58 & evening & 605 \\
\hline 29 & suitable & 1503 & 59 & beauty salon & 590 \\
\hline 30 & tourist & 1470 & 60 & relaxation & 583 \\
\hline
\end{tabular}

Source: characteristic word and word frequency according to the statistical data.

The contents expressed by high-frequency words can be divided into four categories: (1) cruise service, (2) tourists' feelings, (3) travel group, and (4) cruise facilities. Frequent words of cruise service, represented by "service", "tour guide", "enthusiasm", and "thoughtful", reflect the quality of service. Tourists consider the services of "tour guides" to be very important during the shore tour. Frequent words relating to tourists' feelings, represented by "satisfaction", "pleasure", "enjoyment", "leisure", and "relaxation", reflect that cruise tourism is a kind of high-end tourism of leisure experience, and relaxation and leisure vacation are important tourism motives of cruise tourism. The frequent words of travel groups represented by "elderly" and "children" indicate that the current domestic cruise tourism is a travel mode suitable for old people and kids. Frequent words of cruise facilities represented by "buffet", "room", "easy to reach", "shore", "children's area", "program", and "beauty salon" include six elements of tourism including "food, accommodation, transport, travel, shopping, and entertainment" - tourists can experience all kinds of fun on and off the cruise. In addition, "luxury" is a description of cruise facilities by many tourists, which also conforms to the fact that cruise tourism is a high-end tourism mode.

\subsection{Statistics Semantic Network Diagram}

Social network analysis is mainly used to analyze the relationship status of actors in a specific spatial scope and discuss the relevance of internal actors (organizations, groups, communities) and other elements, so as to form a systematic and rich technological method to analyze social network 
relations [57]. We established the relevance of various high-frequency words based on the research of cruise tourists' comments, analyzed the social network relations among them, and started the NetDraw tool to draw the semantic network graph, as shown in Figure 3.

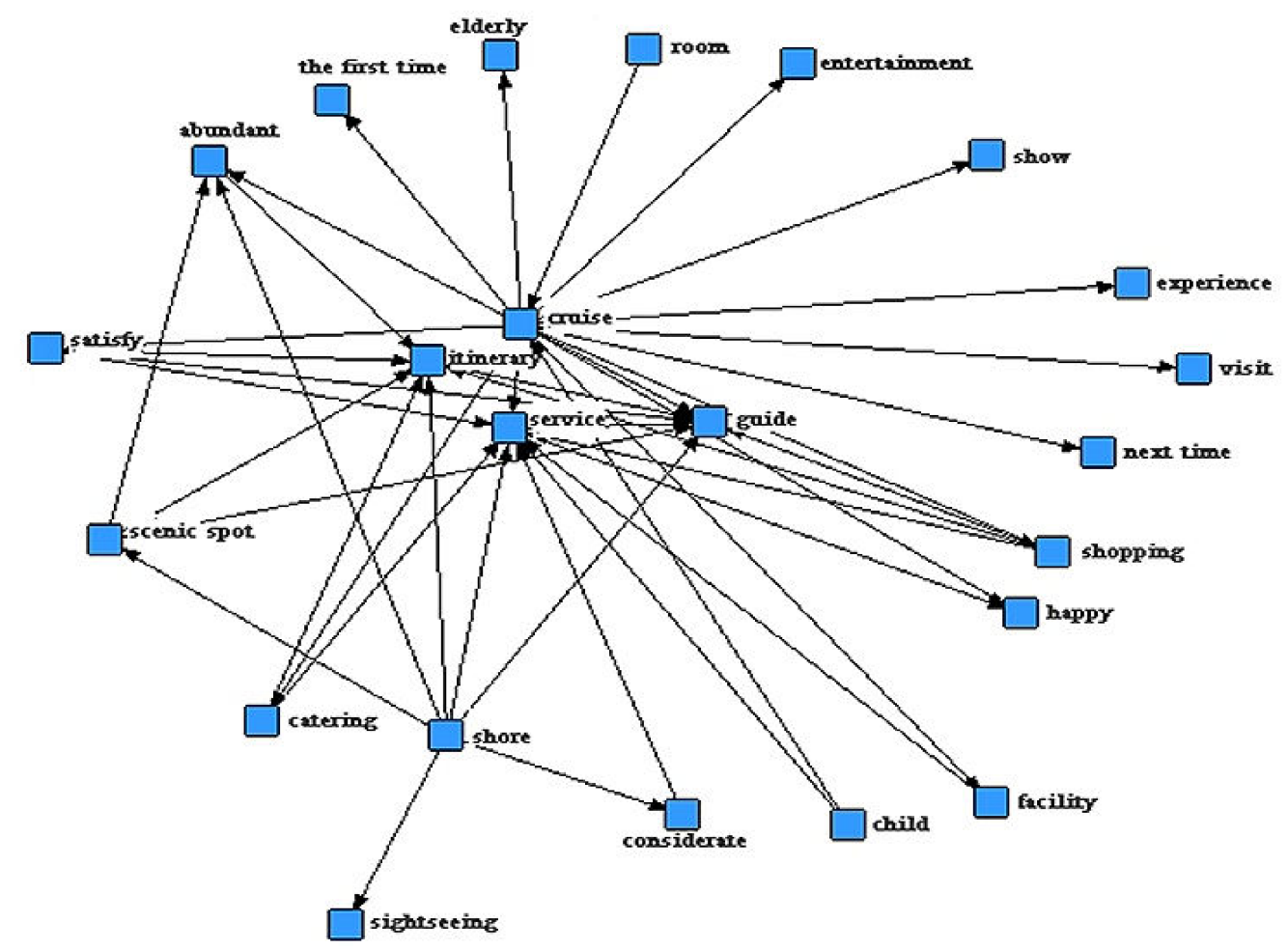

Figure 3. Semantic network graph of tourists' attention to cruise-related factors.

"Cruise", "tour guide", "service", and "itinerary" are the four elements clustering in the center. Although on the surface the parts are relatively concentrated, the whole is decentralized. "Cruise" is closely related to words related to cruise tourism, such as tourists' activities on cruise. The words directly related to it are "happy", "elderly ", "first time", "child", and so on. The frequency of "elderly" and "child" were relatively high, indicating that cruise is a leisure tourism project, and the main tourists involved in cruise tourism in China are old people and children. "The first time" indicates that cruise tourism is still an emerging tourism project in China compared with other tourism projects. "Next time" was used to indicate a desire to "come again", meaning the tourist has the idea of visiting again.

Cruise visitors with different overall satisfaction with their guided tour focused the narrative of their opinion on different tour attributes. Thus, the dominant themes of the cruise passengers delighted with their tour included the performance of the tour guide and the arrangement of the tour, as well as the cruise destination sightseeing [58]. Cruise tourism has high requirements on all links of the activity. "Service" is the center of the activity, and its related words mainly include "itinerary", "tour guide", "thoughtful", and so on. In the cruise, "tour guide" plays a very important role, because a lot of visitors participate in the cruise for their first time as tour groups' members, especially the old people and children, so the tour guide who takes care of cruise tourists at any place and any time appears especially important. The arrangement of the "tour guide" is involved in the "journey", responsible for the "shore", and busy with "management". Centered on the "shore", it is surrounded by words such as "scenic spot", "abundant", and "sightseeing", which reflect the tourist activities after disembarking from the ship. 


\subsection{Emotion Analysis Table Statistics}

The function of "emotion analysis" is mainly reflected in the analysis of semantic rules based on various network reviews, and the specific assignment, through which tourists' emotional state can be fully reflected, and tourists' satisfaction rate can be described based on it [59]. By using the "emotion analysis" function in ROST CM6 software "functional analysis" to conduct emotional analysis on text data, the emotional analysis results of cruise tourists' comments were obtained, as shown in Table 3.

Table 3. Emotional analysis of cruise tourists' online comments.

\begin{tabular}{cccc}
\hline Emotion Type & Proportion & Emotional Segmentation Type & Proportion \\
\hline \multirow{2}{*}{ Positive emotion } & $79.75 \%$ & Ordinary degree (0-10 scores) & $28.43 \%$ \\
& & Moderate degree (10-20 scores) & $34.66 \%$ \\
Advanced degree (above 20 scores) & $16.66 \%$ \\
\hline Neutral emotion & $14.58 \%$ & - & - \\
\hline \multirow{2}{*}{ Negative emotion } & $5.67 \%$ & Ordinary degree (0-10 scores) & $3.50 \%$ \\
& & Moderate degree (10-20 scores) & $2.17 \%$ \\
Total & $100 \%$ & Moderate degree (10-20 scores) & $0.00 \%$ \\
\hline
\end{tabular}

The emotional analysis on the samples was conducted and such textual comments were found to have implicit characteristics. Through the analysis of Table 3, it can be concluded that the emotional tendency of tourists towards cruise tourism is mostly positive, accounting for $79.75 \%$, which shows that tourists are relatively satisfied with cruise tourism.

The emotional words reflecting positive emotions in the sample were "satisfied", "considerable", "happy", "leisure", "abundant", "luxury", "enjoy", and "relax". Among them, "satisfied" and "considerable" reflect the thoughtfulness of cruise staff and tour guides in cruise service. "Happy" indicates that tourists were in a positive mood when experiencing cruise travel. "Leisure" and "enjoyment" indicate that cruise tourism is a high-end leisure travel mode. "Luxury" and "abundant" reflect the variety of cruise entertainment facilities and programs.

The emotional vocabulary of negative emotions included "crowded", "wasted", and "worried". Among them, "crowded" reflects that tourists think that some entertainment facilities and programs have too many participants and they feel very uncomfortable when waiting in line or participating in activities. This also reflects the negligence of staff in their work, failing to guide tourists to have good order. Secondly, "crowded" also shows in the activities of the scenic spots on the shore, tourists think that the arrangement of some scenic spots for tourists are too unorganized, and the arrangement of the tour time is too short, so the tourists have not enough time to enjoy the views. "Wasted" is reflected in catering. It shows that some tourists waste food when enjoying buffets, meanwhile they also say that the situation is better than before. "Worried" indicates that, on one hand, tourists feel nervous that the weather is uncertain, or cruises sometimes have slight swings while encountering waves; on the anther hand, the profile reflects that most tourists are participating in cruise tourism for their first time, showing their "worries" about their first experience.

\subsection{Interview and Online Texts in "World Dream"}

The interview topic was the satisfaction evaluation of the cruise trip from SSP to Vietnam on December 9th to 13th, 2018 by "World Dream". According to the influencing factors of cruise tourists' satisfaction by Teye and Leclerc (1998), overall, passengers' expectations are met or exceeded but there are key product and service delivery areas which provided cruise ship guests with the most satisfaction [60]. 
We conducted semistructured interviews with 54 tourists, concentrating on the clustered four themes of "cruise"," service"," itinerary", and "guide". Below are some typical comments representing the four themes:

"I'm going to travel as much as I can while I'm healthy. Cruises are very suitable for us elderly. We used to be not able to afford it, but now we're enjoying it on a cruise." (M1, 68 years old)

"My son is too busy to accompany me to travel everywhere, so I take a cruise with my wife and grandson. My son has paid for it. The pace of Shenzhen is too fast. My son and daughter-in-law have money but no time. I can understand that." (M4, 71 years old)

"I'm 66 years old, and this time, my granddaughter and I are on the cruise. I would have been worried, but later I realize that it is unnecessary because the cruise is well managed and the service is so sweet." (F12, 66 years old $)$

These contents reflect that China's senior citizen gradually update their travel concept with the growing spending power. Besides, middle-aged couples are willing to pay for their elderly parents and young children on the cruise. Grandparents and grandkids two generations together enjoy their cruise service very much.

"The second time I take the world dream, my son is very excited every time. I didn't go ashore last time, but this time it takes for a long time. If you want to save time, you'd better follow the tour group." (F20, 37 years old)

"I really do not know how to travel without itinerary and tour guide. I take a cruise just for sightseeing to the foreign country. I get it! Just look at my pictures." (M33, 48 years old)

"The tour leader is very responsible. He is very concerned about the elderly and children in the team. He reminds us of the precautions again and again." (F4, 60 years old)

"Tour guide information is well prepared but lack of cruise experience." (M42, 55 years old)

"The tour guide of the onshore visit is very warm-hearted and considerate. She introduces us the local architecture and famous snacks. Although she asks us to buy something on the way, we are very satisfied with her service." (M17, 62 years old)

"We usually have the habit of carrying some gifts to friends and relatives back to home while travelling, which is manifested in buying souvenirs in local areas or duty-free shop. But duty-free shop is too crowded, and the sales staff could not provide everyone with thoughtful service, thus affecting our satisfaction." (F50, 56 years old)

The above narratives of the reviewers show that Chinese tourists who participated in cruise tours mainly do so for sightseeing tours, which attach great importance to destination attractions. They were satisfied with the attitude of tour guides, who were diligent and responsible, especially while embarking and disembarking. The itinerary was arranged in an orderly way, and there were relevant reminders on matters needing tourists' attention. The problem of guide and shopping needs to be improved.

In order to further explore tourists' satisfaction with cruise tourism-related factors, we studied cruise tourists' satisfaction from five aspects according to Ctrip's satisfaction rating system. We chose 537 comments about "World Dream", excluding duplicates and comments irrelevant to the topic, as shown in Table 4.

Generally speaking, tourists were satisfied with the cruise tourism. As one of the six elements of tourism, catering draws close attention of Chinese people. Tourists mainly made comments from the aspects of taste, price, environment, and service, $77.84 \%$ of them were satisfied, $5.40 \%$ were not satisfied 
with the food onboard due to inconsistent taste, crowded buffet line, and wasting food. According to personal experiences and interviews with tourists, some Chinese restaurants' cooking taste were not authentic, and most of the catering on the cruises were mainly buffet and the taste of the dishes on the buffet was affected if they were put out for a long time.

Table 4. Ctrip: tourists' satisfaction evaluation of "World Dream" cruise.

\begin{tabular}{cccc}
\hline Evaluation Object & Satisfaction Degree & Frequency & Percentage \\
\hline \multirow{3}{*}{ Cruise catering } & Satisfied & 418 & $77.84 \%$ \\
& Ordinary & 90 & $16.76 \%$ \\
& Unsatisfied & 29 & $5.40 \%$ \\
\hline \multirow{3}{*}{ Entertainment } & Satisfied & 389 & $72.44 \%$ \\
& Ordinary & 110 & $20.48 \%$ \\
& Unsatisfied & 38 & $7.08 \%$ \\
\hline \multirow{2}{*}{ Cruise room } & Satisfied & 443 & $82.50 \%$ \\
& Ordinary & 82 & $15.27 \%$ \\
& Unsatisfied & 12 & $2.23 \%$ \\
\hline \multirow{2}{*}{ Cruise service } & Satisfied & 419 & $78.03 \%$ \\
& Ordinary & 108 & $20.11 \%$ \\
& Unsatisfied & 10 & $1.86 \%$ \\
\hline \multirow{2}{*}{ Overall evaluation } & Satisfied & 426 & $79.33 \%$ \\
& Ordinary & 72 & $13.48 \%$ \\
\hline
\end{tabular}

In total, $72.44 \%$ of the tourists were satisfied with the fun on board, including entertainment facilities and performances, which were rated as "rich and relaxing". However, $7.08 \%$ of the tourists were not satisfied, saying the Internet facilities on board were too expensive and slow. Meanwhile, some entertainment facilities were not open. For the rooms on the cruise, $82.50 \%$ of the tourists were satisfied with staff's attitude, and the evaluation generally showed neatness, cleanness, and brightness, etc. Only $2.23 \%$ of the visitors were dissatisfied because of the small space and the feeling of shaking while sleeping. The cruise space is limited to the cabin, so it cannot be compared with the hotel suite, but in general, the small house was complete, the room layout was reasonable, and the equipment was complete; large cruises generally have no obvious rocking sensation in their rooms, except in extreme weather.

As a high-end tourism activity, $78.03 \%$ of tourists were satisfied with the onboard service. According to the semantic network graph in Figure 3, "service" is connected with "thoughtful" and "satisfied", indicating that tourists had a high evaluation of the cruise service. Only $1.86 \%$ of the tourists were dissatisfied, regarding that many of the attendants on the ship were foreigners and the language exchange was not convenient. Finally, $79.33 \%$ of the tourists were satisfied with the activity of cruise tourism, believing that cruise tourism is "very relaxing", "suitable for the elderly and children", and "very enjoyable". In total, $7.26 \%$ of tourists thought cruise travel was "boring" and "expensive". The analysis results show that tourists' satisfaction with cruise tourism was far higher than other tourism activities, which was related to the high quality service and high-end positioning.

To sum up, it can be concluded that there was no obvious difference between the information obtained from the interview and the online text information in "World Dream".

\section{Discussion}

The paper is put forward under the background of the rapid development of cruise tourism in China and the promotion of the cruise industry in Shenzhen. There are several possible explanations for some arguments. 
First, why choose a cruise home port to study the development of cruise tourism? Cruise home port is a node of the cruise industry chain, not only the carrier of cruise owners and gathering place of tourists, but also an important resource integrator for the cruise economic system. SSP is located in the subtropical area, navigable all year round, and its radius of potential consumers come from China's economically developed and active regions with a promising future $[15,17,18]$.

Second, why is it based on value chain theory and dependent on an online text analysis and interview method? Nowadays cruise tourism is an emerging tourism business in China. Most Chinese tourists are experiencing cruise tourism for the first time and their tourism motivation is to mainly get the tourism experience. Based on the "tourist source" and "procurement" aspects of the value chain theory [25], we got deep into the minds of cruise tourists through data collection and analysis, together with face-to-face interviewing onboard and offshore for those who could not or would not write online [54,55]. According to the research for Chinese tourists, senior citizens and kids and parents are two emerging markets. Meanwhile, enriching cruise entertainment facilities, improving service quality, attaching importance to the cultivation of leisure culture, and setting up duty-free shopping centers are by any means necessary $[7,8]$.

Third, what is the relationship between SSP cruise tourism development and sustainability? Shenzhen Ocean Development Planning (2013-2020) put forward the key points of the development of the marine industry for cruise and related industrial facilities, including the construction of cruise home port service facilities, implementation of a consumption strategy, expanding cruise yacht upstream and downstream industry chains, speeding up the cruise home port and the public service facilities construction, and promoting the cruise customs clearance facilitation. SSP is facing important development opportunities [12,14,21].

\section{Conclusions}

Using ROST CM6 software to conduct social network analysis on the comments of cruise tourists, it was found that "cruise", "service", "itinerary", and "tour guide" are the core words, and relevant tourism activities are carried out around these four aspects, which are consistent with the statistical analysis results of high-frequency words. From the perspective of emotion analysis and the rating system of satisfaction, it further discusses the important elements of who are cruise target tourists in Southern China and what they care most about in cruise value chain.

\subsection{Chinese Senior Citizens Market}

The elderly are the main consumer group of Chinese cruise tourism, which is popular with families from different generations. In high-frequency word statistics, "elderly" and "children" were sorted at 10th and 20th. From the interview, most elderly cruise visitors felt proud of their cruise trip, while some of them travel with their grandson or granddaughter, namely between the two generations because parents did not participate. The elderly generally have enough money, leisure time, and a strong desire to take the cruise trips. The long-haul cruise will satisfy the need of the newly retired to see the outside world. Chinese grandparents, on the other hand, are so tired of taking care of their grandchildren that their children volunteer to help them relax by taking a cruise during the summer and winter holidays. Old people are willing to take advantage of their health at the time to take the cruise and enjoy the happiness of being served in more luxurious conditions than usual travel life.

\subsection{Marketing to Kids and Parents}

Based on the above analysis, parent-child cruise culture needs to be constructed and strengthened. Aleksander (2019) concluded a deeper understanding of children's cruise experience in the following phases: the precruise decision and planning phase; the onboard engagement phase; and the reinterpretation and evaluation phase [50]. The basic educational concept of the Chinese people is that the family gives priority to children, which is reflected in the investment of the family's money, time, and energy for the growth of children. Cruise is a way for children to travel with their parents, which 
meets the rigid demand of China's parent-child travel market. It not only helps children broaden their horizons, increase their abilities, learn etiquette, acquire knowledge, and make friends, but it is also an important means to improve the relationship between parents and children, enhance family cohesion, and plan their children's future. Children and parents participate in the planning and decision-making of cruise travel together, attend a formal welcome and farewell parties together on the cruise, take part in all kinds of activities carefully designed by cruise staff, and visit different natural scenery and local customs onshore. Moreover, the cruise lines are abundant, duration of the journey is flexible, and prices depend on people. All of these features provide plenty of promising opportunities for the Chinese kids and parents market.

\subsection{Shopping and Facilities}

"Shopping" and "facilities" ranked the seventh and eighth in the statistics of high-frequency words, reflecting their importance as two of the six elements of tourism. Shopping is strongly demanded, but duty-free shops are crowded. It can be seen from the above analysis that the types and services of duty-free shops on cruise ships need to be improved. Park and Lee (2019) demonstrated that the respondents placed the highest value on having a variety of shopping items in duty-free shops onboard [61]. Relying on the policy advantages of China's cruise tourism development experiment, duty-free shopping centers for cruise tourists near the home port could be set up so as to improve the tourist's shopping experience. In addition, it is essential to design products creatively, emphasize differentiation, and enrich cruise shopping and entertainment facilities on and off the cruise. There are still some unsatisfactory factors, though it is generally in a controllable state. "Entertainment" on board should be strengthened because $7.08 \%$ tourists felt unsatisfied. Enriching recreational facilities for the elderly and children is necessary. For tourists, the reason they can enjoy leisure activities on the cruise is due to use of the entertainment facilities and related carriers, and the satisfaction of tourists mainly depends on the above factors.

\subsection{Tour Guide Service}

From the statistics, the high-frequency words "scenic spot" and "shore" were located in the forefront, closely linked to the semantic web "guide" shown in Figure 3. It shows from the interviews that the essence of the cruise product is the experience. However, more and more Chinese tourists accept and try leisure and relaxation tourism style. Chinese tourists still rely on tour guides in cruise tourism, so cruise companies and travel agencies should strengthen the skills training of tour guides and tour leaders, so as to improve tourists' sense of experience. On the other hand, cruise lines and home ports should attach importance to brand building, adhere to quality service standards, and provide humanized services for tourists. In short, continuous optimization of service quality and improvement of service level from various aspects is the long-term task of cruise tourism development, and also an important countermeasure to improve cruise tourists' satisfaction.

In general, the aim of this research was to find the driving force conducive to the sustainable development of cruise tourism in the "tourist source" and "procurement" of the value chain. From this study, "tourist source" of the Chinese senior citizens market and marketing to kids and parents are worth pursuing. Especially in the context of Chinese culture, families pay more and more travel expenses for the elderly and children, thus creating a huge market.

In terms of "procurement", we focused on the improvement of the shopping conditions on cruise and home ports, increasing the space of shopping places, offering a variety of goods and the creativity of commodities, improving the facilities of cruise and home ports, enhancing the service awareness and level of tour guides, and upgrading the satisfaction of tourists and the rate of revisiting, so that tourists are willing to play important role in word-of-mouth publicity. 


\section{Research Contributions}

First, at the level of strategic cooperation, there is a symbiotic relationship between the cruise home port and the cruise company on the industrial chain. As the docking port of the cruise company, the home port must provide first-class connection services, understand the whole process of the cruise company, comb the core link of the value chain-tourists source and procurement-and play the role of information flow and technology flow.

Strategic attention to enhancing information technology (IT) competency and knowledge management (KM) will contribute to the service supply chain (SSC) (coordination, collaboration, and efficiency) practice of the tourism industry [62]. It promotes undoubtedly the development of the cruise industry in the Internet era. In addition, information flow is one of the three important flows (materials, capital, and information) in the supply chain, which plays a crucial role in the performance of the supply chain, achieving a high degree of integrity and collaboration among members of the supply chain [63]. It is necessary to establish long-term information exchange and strategic alliance within the cruise industry system and among enterprises to achieve win-win cooperation.

Second, at the operational level, especially at the sales level, the cruise home port can assume the role of organizer. The cruise home port organization establishes cruise alliance, gathers the cruise company's sales agent, and forms the joint force in the marketing on the basis of the cultural organization identification.

For companies that plan to expand the number of sustainable products they buy and sell, building a supportive organizational culture can do more with less. When the situation can be achieved, it depends on whether the sustainability of the organizational culture can help the organization meet the requirements of product and service quality, especially when the product has applicability to its target market, the service specialty achieves professionalism, and the cooperative relationship forms trust and dependence [64]. The cruise home port can work closely with cruise companies, sales agents and other relevant enterprises to jointly promote the creation of cruise products and service ecospheres.

Third, at the practical level, the implementation of a green supply chain depends on infrastructure procurement by building value-adding shopping centers, training tour guides, and cruise staffs, seizing China's emerging elderly market and parent-child market. By all means, customer value in tourism and hospitality can broaden dimensions and stretch the value-satisfaction-loyalty chain [65].

Fourth, in the long run of sustainable development, the relationship between value chain appreciation and incremental growth can be derived from the model to develop the cruise tourism industry. Cruise-related companies' evolvement of the single chain development path can be reproducible in terms of the horizontal and vertical chain cooperation development path by sharing customer resources, meeting the demand of the sustainable development of the supply chain, and by forming a single profit on cost and profit model to mutually beneficial cooperation from low to high growth.

\section{Limitations and Future Research}

In this paper, a combination of quantitative research and qualitative research was adopted to seek favorable factors for passenger sources and procurement in the value chain of cruise-related companies in the direction of win-win development of cruise ships and home ports. First, through text analysis, the evaluation of cruise tourists on the Internet was captured from the big data of Ctrip, and a large-scale, frame-based, and broad-line survey was conducted for the online crowd. Then, through face-to-face interviews with cruise tourists, small-scale, in-depth and detailed research was conducted on the elderly and parent-child market, with diversified and extensive sampling. By analyzing the run-length of cruise tourists experience feedback, the most closely watched tourist market and their hardware and software facilities were extracted to draw the attention of the cruise, home port, and other related enterprises, forming the value chain cooperation with joint effort, pushing up the value chain proliferation and value-added effect. SSP has been exploring this aspect, but there are not many cruise-related enterprises with the awareness of these value chains. This paper hopes to provide some 
ideas and suggestions, so as to make cruise-related enterprises move towards multiwin cooperation from the aspects of strategy, operation, and implementation.

Compared with the existing literature, the innovation of this paper lies in taking SSP as an example and deeply exploring the core elements of cruise tourism value chain based on network text analysis and interview, which not only focused on the study of cruise tourists in Southern China, but also enriches cruise value chain theory. However, this paper has certain limitations. Ctrip network comments from cruise tourists were selected without considering other web sites, and the elderly and children could not share tourism feeling through network - these, to a certain extent, affect the research results, so to some extent the face-to-face interview method makes up for the deficiency.

If only online review data are used for cruise tourism, it is difficult to produce good results. After all, the structure and content of online review cannot present more information and reveal the deep problems of cruise tourism. In the next step, the government, cruise companies, cruise home port, and tourists should be investigated and interviewed in various ways to find financial statistics for a more objective and comprehensive study.

Author Contributions: Conceptualization and methodology, Y.L. and X.J.; Writing, review and editing, Y.L. and E.D.; Data curation and investigation, S.L. and Y.L. All authors have read and agreed to the published version of the manuscript.

Funding: This research was funded by Sichuan University Business School Innovation Project, grant number LH2018006; Guangdong Higher Education Teaching Reform Project, grant number 201627334.

Acknowledgments: The authors would like to thank Zengxian Liang, Chenglu Wang, Yongge Niu, Zhimin Zhou, and Quanbao Niu for their valuable insights and comments on the manuscript; three anonymous reviewers' review.

Conflicts of Interest: The authors declare no conflict of interest.

\section{References}

1. Perea, M.; Rosa, J.; Andrade, M. Potential of public transport in regionalisation of main cruise destinationations in Mediterranean. Tour. Manag. 2019, 74, 382-391. [CrossRef]

2. Taheri, B.; Hosany, S.; Altinay, L. Consumer engagement in the tourism industry: New trends and implications for research. Serv. Ind. J. 2019, 39, 7-8. [CrossRef]

3. Sharples, L. Research note: Customer experience management in cruise pre-consumption. Int. J. Cult. Tour. Hosp. Res. 2019, 13, 235-243. [CrossRef]

4. Tao, S.; Kim, H. Cruising in Asia: What can we dig from online cruiser reviews to understand their experience and satisfaction. Asia Pac. J. Tour. 2019, 24, 514-528. [CrossRef]

5. Jeronimo, E.; Antonio, G.; Andrea, M. Cruise traffic seasonality patterns in the Western Mediterranean and the Adriatic Sea: A Challenge to Port Operators. Coast. Manag. 2019, 47, 362-386.

6. Jeon, J.; Duru, O.; Yeo, G. Cruise port centrality and spatial patterns of cruise shipping in the Asian market. Marit. Policy Manag. 2019, 46, 257-276. [CrossRef]

7. Nagy, J.; Oláh, J.; Erdei, E.; Máté, D.; Popp, J. The role and impact of industry 4.0 and the Internet of Things on the business strategy of the Value Chain-The case of Hungary. Sustainability 2018, 10, 3491. [CrossRef]

8. Berne-Manero, C.; Gomez-Campillo, M.; Marzo-Navarro, M.; Pedraja-Iglesias, M. Review the online tourism value chain. Adm. Sci. 2018, 8, 48. [CrossRef]

9. Yu, C.-P.; Cole, S.T.; Chancellor, C. Resident support for tourism development in rural Midwestern (USA) Communities: Perceived tourism impacts and communitity quality. Sustainability 2018, 10, 802. [CrossRef]

10. Chen, J.; Guan, J.; Xu, J.B.; Clergeau, C. Constructing the green supply chain for rural tourism in China: Perspective of front-back stage decoupling. Sustainability 2018, 10, 4276. [CrossRef]

11. Li, N. Mainland Chinese cruise passengers' onshore experience. Tour. Recreat. Res. 2019, 44, $217-231$. [CrossRef]

12. Guo, X. Explore China cruise development of future by innovation and reform. China Ports 2019, 1, 28-30.

13. Artal-Tur, A.; Miguel Navarro-Azorin, J.; Maria Ramos-Parreno, J. Estimating the impact of cruise tourism through regional input-output tables. Int. J. Tour. Hosp. Res. 2019, 30, 235-245. [CrossRef]

14. Sun, X.; Feng, X.; Gauri, D. The cruise industry in China: Efforts, progress and challenges. Int. J. Hosp. Manag. 2014, 42, 71-84. [CrossRef] 
15. Yin, F.; Mei, S. Shekou Prince Bay will build up world-class cruise home port. J. Waterw. Harb. 2016, 37, 254.

16. Zhang, Y. A study on the development of cruise tourism industry in Hainan Province in the context of free trade zone(port) construction with Chinese characters. East China Econ. Manag. 2018, 32, 180-184.

17. Xu, Y.; Ban, M.; Lu, L. Research progress on Chinese cruise tourism. Yunnan Geogr. Environ. Res. 2018, 30, 9-17.

18. Zhang, M.; Liu, Y. Review and evolution of researches on the development of cruise tourism. J. Baoshsan Univ. 2014, 33, 76-81.

19. Luo, P.; Zhang, Y.; She, S. Study of SWOT analysis and countermeasures on cruise tourism in the west of Straits Economic Zone. J. Chongqing Norm. Univ. 2011, 28, 82-87.

20. Pan, Q.; Fan, X. Development strategy of cruise tourism in Xiamen. China Ports 2018, 1, $29-31$.

21. Wei, R.; Cheng, C.; Yin, Y. Current situation and strategies of cruise tourism in China. Spec. Zone Econ. 2018, 2, 80-83.

22. Kang, S. A contents analysis of research trends of cruise tourism in Korea: Focused on the KCI Journals. J. Tour. Manag. Res. 2019, 23, 333-352. [CrossRef]

23. Ignacio, R.; Valentin, M.; Francisco, C. Prediction of the impact on air quality of the cities receiving cruise tourism: The case of the Port of Barcelona. Heliyon 2019, 5, e01280.

24. Hung, K.; Wang, S.; Guillet, B. An overview of cruise tourism research through comparison of cruise studies published in English and Chinese. Int. J. Hosp. Manag. 2019, 77, 207-216. [CrossRef]

25. Liu, Y.; Jie, X. Travel agency strategic innovation study based on value chain theory: An empirical study in Shenzhen. In Proceedings of the 3rd IEEE International Conference on Information Management, Chengdu, China, 21-23 April 2017; pp. 42-45.

26. Penco, L.; Profumo, G. Mergers, acquisitions and alliances in the cruise tourism industry. Tour. Hosp. Res. 2019, 19, 269-283. [CrossRef]

27. Sun, X.; Feng, X. Cruise tourism in China: Present situation of studies and prospect. Tour. Trib. 2012, 27, 101-112.

28. Zhang, Y.; Ma, B.; Fan, Y. Basic characteristics development trends and implications of cruise tourism. J. Beijing Int. Stud. Univ. 2010, 32, 26-33.

29. Zhang, Y.; Kou, M.; Ma, B. A study review on overseas cruise tourism market. Tour. Trib. 2012, 27, 94-100.

30. Li, M. Analysis and measurement of cruise tourism satisfaction in China. In Proceedings of the 2015 China Tourism Science, Beijing, China, 24 April 2015; pp. 214-220.

31. Guan, S.; Wu, X. Chinese cruise tourists satisfaction survey. Ind. Sci. Trib. 2014, 13, 127-128.

32. Hu, S.; Zheng, Y.; Huang, B.; Xu, X. Zhoushan cruise tourists motion, satisfaction and revisit willingness Research. China Water Transp. 2018, 18, 31-33.

33. Liu, B.; Schroeder, A.; Pennington, L. Cruise line customers' responses to risk and crisis communication messages: An application of the risk perception attitude framework. J. Travel Res. 2019, 58, 849-865.

34. Chen, J.; Petric, J.; Papathanassis, A.; Li, X. A meta-analysis of the direct economic impacts of cruise tourism on port communities. Tour. Manag. Perspect. 2019, 31, 209-218. [CrossRef]

35. Han, H.; Yu, J.; Koo, B. Vacationers' norm-based behavior in developing environmentally sustainable cruise tourism. J. Qual. Assur. Tour. 2019, 20, 89-106. [CrossRef]

36. Petrick, J. Segmenting cruise passengers with price sensitivity. Tour. Manag. 2005, 26, 753-762. [CrossRef]

37. Shen, Y. The Theme Park Tourists Satisfaction Influencing Factors and Promotion Path Study Based on Online Text Analysis: The Case of Wuhu City. Master's Thesis, Nanjing Normal University, Nanjing, China, 2018.

38. Nolich, M.; Spoladore, D.; Carciotti, S. Cabin as a home: A novel comfort optimization framework for IoT equipped smart environments and applications on cruise ships. Sensors 2019, 19, 1060. [CrossRef] [PubMed]

39. Nur, A.; Dinesh, K.; Webster, S. Empirical evidence of revenue management in the cruise line industry. J. Travel Res. 2019, 58, 104-120.

40. Miles, S. Immersive narratives of 'self-work' in an experience society: Understanding the cruise ship experience. Leis. Stud. 2019, 38, 523-534. [CrossRef]

41. Yan, Q. Cruise ship tourism (2nd edition). Leis. Stud. 2019, 38, 288-290. [CrossRef]

42. Papathanassis, A. Guest-to-guest interaction on board cruise ships: Exploring social dynamics and the role of situational factors. Tour. Manag. 2012, 33, 1148-1158. [CrossRef]

43. Han, H.; Hyun, S. Cruise travel motivations and repeat cruising behaviour: Impact of relationship investment. Curr. Issues Tour. 2019, 22, 786-805. [CrossRef] 
44. Hosany, S.; Witham, M. Dimensions of cruisers'experiences, satisfaction, and intention to recommend. J. Travel Res. 2010, 49, 351-364. [CrossRef]

45. Sanz-Blas, S.; Buzova, D.; Carvajal-Trujillo, E. Familiarity and visit characteristics as determinants of tourists' experience at a cruise destination. Tour. Manag. Perspect. 2019, 30, 1-10. [CrossRef]

46. Sanz-Blas, S.; Buzova, D.; Schlesinger, W. The sustainability of cruise tourism onshore: The impact of crowding on visitors' satisfaction. Sustainability 2019, 11, 1510. [CrossRef]

47. Fernandez, G.; Sanchez, S.; Callejon, G. Cruise passengers' intention and sustainable management of cruise destinations. Sustainability 2019, 11, 1929. [CrossRef]

48. Buzova, D.; Sanz-Blas, S.; Cervera-Taulet, A. Does culture affect sentiments expressed in cruise tours' eWOM? Serv. Ind. J. 2019, 39, 154-173. [CrossRef]

49. Chua, B.; Lee, S.; Kim, H. Investigation of cruise vacationers' behavioral intention formation in the fast-growing cruise industry: The moderating impact of gender and age. J. Vacat. Mark. 2019, 25, 51-70. [CrossRef]

50. Radic, A. Towards an understanding of a child's cruise experience. Curr. Issues Tour. 2019, 22, $237-252$. [CrossRef]

51. Brejla, P.; Gilbert, D. An exploratory use of web content analysis to understand cruise tourism services. Int. J. Tour. Res. 2014, 16, 157-168. [CrossRef]

52. Tang, C.; Weaver, D.; Shi, F. Constraints to domestic ocean cruise participation among higher income Chinese adults. Int. J. Tour. Res. 2019, 21, 519-530. [CrossRef]

53. Wang, R.; Huang, P.; Hu, J.; Li, Y. Study on rural tourism experience of Wuyuan County based on online travel note. Resour. Sci. 2019, 41, 372-380.

54. Gursoy, D. A critical review of determinants of information search behavior and utilization of online reviews in decision making process. Int. J. Hosp. Manag. 2019, 76, 53-60. [CrossRef]

55. Xiang, Z.; Du, Q.Z.; Ma, Y.F.; Fan, W.G. A comparative analysis of major online review platforms: Implications for social media analytics in hospitality and tourism. Tour. Manag. 2017, 58, 51-65. [CrossRef]

56. Sun, X.; Ni, R. Chinese cruiser's product cognition, emotional expression and brand image perception: A web content analysis. Geogr. Res. 2018, 37, 1159-1180.

57. He, M.; Zhang, Y.; Wu, M. Study on experience of cruise tourist based on web text analysis. Tour. Forum 2017, 10, 51-62.

58. Buzova, D.; Sanz-Blas, S.; Cervera-Taulet, A. 'Tour me onshore': Understanding cruise tourists' evaluation of shore excursions through text mining. J. Tour. Cult. 2019, 17, 356-373. [CrossRef]

59. Sun, X.; Ni, R. Onboard attibutes/criteria of cruise ships and cruiser's satisfaction evaluation. Stat. Inf. Forum 2017, 32, 116-122.

60. Teye, V.; Leclerc, D. Product and service delivery satisfaction among North American cruise passengers. Tour. Manag. 1998, 19, 153-160. [CrossRef]

61. Park, S.; Lee, W.; Moon, J.; Heo, J. Examination of Chinese cruise tourists' attributes using a Choice Experiment. Sustainability 2019, 11, 3621. [CrossRef]

62. Jalilvand, M.; Pool, J.; Javad, K.; Khodadadi, M. Information technology competency and knowledge management in the hospitality industry service supply chain. Tour. Rev. 2019, 74, 872-884. [CrossRef]

63. Farajpour, F.; Taghavifard, M.; Yousefli, A. Information sharing assessment in supply chain: Hierarchical Fuzzy Rule-Based System. J. Inf. Knowl. Manag. 2018, 17, 1850002. [CrossRef]

64. Richards, P.; Font, X. Sustainability in the tour operator-Ground agent supply chain. J. Sustain. Tour. 2019, 27, 277-291. [CrossRef]

65. Gallarza, M.; Arteaga, F.; Gil-Saura, I. Customer value in tourism and hospitality: Broadening dimensions and stretching the value-satisfaction-loyalty chain. Tour. Manag. Perspect. 2019, 31, 254-268. [CrossRef]

(C) 2020 by the authors. Licensee MDPI, Basel, Switzerland. This article is an open access article distributed under the terms and conditions of the Creative Commons Attribution (CC BY) license (http://creativecommons.org/licenses/by/4.0/). 